(C) 1984. The Genetical Society of Great Britain

\title{
VARIATION IN SPONTANEOUS MUTATION AND REPAIR IN NATURAL POPULATION LINES OF DROSOPHILA MELANOGASTER
}

\author{
R. C. WOODRUFF,* JAMES N. THOMPSON, JR. † MARK A. SEEGER* \\ AND WILLIAM E. SPIVEY $\dagger$ \\ * Department of Biological Sciences, Bowling Green State University, Bowling Green, Ohio \\ 43403. † Department of Zoology, University of Oklahoma, Norman, Oklahoma 73019
}

Received 20.x.83

\section{SUMMARY}

To measure the possible correlation between genetic damage and repair ability in natural populations of a eukaryote, we compared the spontaneous frequency of sex-linked recessive lethal mutations and male recombination, which is associated with DNA transposable element induced chromosome breakage, with DNA repair efficiency in isofemale lines of a winery population of Drosophila melanogaster from Australia. Repair efficiency was measured by maternal effects on ring-X chromosome loss. Significant amounts of genetic variability for spontaneous rates of genetic change and for repair ability were observed in the isofemale lines collected during periods of low and high population density. However, there were no correlations between repair ability and rates of genetic damage. Possible reasons for the absence of correlation are discussed, along with the observations that: (a) the frequency of lethal mutations and ring-X chromosome losses were significantly higher in the small, resident population; (b) the rates of ring chromosome losses and especially lethal mutations are uniform over periods of time; (c) and inbreeding of isofemale lines leads to a reduction of the high spontaneous mutation rates.

\section{INTRODUCTION}

Variation in the rate of spontaneous mutation has been documented in natural populations of Drosophila melanogaster (Woodruff et al., 1983) and other species (Neel, 1983). Although age, temperature, physiological condition and other non-genetic factors can influence mutation rates, the genetic constitution of the individual is undoubtedly of paramount importance (Woodruff and Thompson, 1982a). Two genetic factors, in particular, have recently received extensive attention-repair defective mutations (Generoso et al., 1980; Mason, 1980; Quah et al., 1980; Smith et al., 1980; Würgler and Graf, 1980; Vijayalaxmi et al., 1983) and mutator activity (see Green, 1976; Neel, 1983; Woodruff et al., 1983 for reviews).

In this study we compare the spontaneous sex-linked recessive lethal mutation frequency, DNA repair efficiency, and mutator activity associated with male recombination in two sets of isofemale strains. There were two major objectives. First, we wanted to determine whether there is a clear correlation between repair ability and spontaneous rates of genetic change in strains from natural populations. This objective is important because it has been postulated that at least 90 per cent of spontaneous mutations in some eukaryotes are caused by misrepair of spontaneous lesions (Quah et al., 1980). Second, we hoped to identify strains that differed significantly in either repair or mutation rates so that the genetic determinants of strain 
variation could be analysed in more detail. The isofemale strains we tested were obtained from a winery in Australia and represent collections from a small "resident" population and from the larger population that is produced by immigrants attracted at harvest time.

\section{Materials and Methods}

Twenty isofemale lines, each originating from a single female inseminated before capture, were collected from the Chateau Tahbilk winery, Victoria, Australia, and were kindly supplied by P. A. Parsons. The first set, numbered CT-1 through CT-10, was collected in October, 1979, before the grapes ripened and the resident population was small. The second set, numbered CT-102 and above, was collected in May, 1980, after migrants had caused an explosive increase in population size at harvest time. All cultures were maintained on cornmeal, molasses, and agar medium at $25 \pm 1.0^{\circ} \mathrm{C}$ in 8 -dram culture vials or half-pint bottles seeded with live yeast.

The frequency of spontaneous sex-linked recessive lethal mutations was measured in each of the isofemale lines by mating Chateau Tahbilk (CT) males to females homozygous for the $\mathrm{X}$-chromosome balancer Basc (In (1) $s c^{S l L} s c^{8 R}+S, s c^{S l} s c^{8} w^{a} B$ ). Individual $F_{1}$ females were then mated to Basc males, and the $F_{2}$ progeny were scored for the presence of $B^{+}$males. Absence of wild-type males (out of a total of at least 20 males scored per culture) indicated that a lethal mutation had occurred in the original CT male parent.

Spontaneous ring chromosome loss was used as a measure of DNA repair ability in these $20 \mathrm{CT}$ lines. Although the exact mechanism of interaction of repair and ring chromosome loss is unclear, the relationship between ring loss and repair can perhaps best be understood by considering the following example (Leigh, 1976).

Chromosome breakage in a ring- $X$ male will initially produce a rod chromosome. If this breakage is not repaired by maternal enzymes after fertilization, the chromosome will be lost or the breakage event will result in dominant lethality. Repair, on the other hand, can have several outcomes. "Correct" repair will result in the ring-X being reformed, and the offspring will be an XX female. Yet, if there is torsion of the chromosomes before repair is completed, a dicentric chromosome (caused by a $180^{\circ}$ rotation before repair) or interlocking rings (by a $360^{\circ}$ rotation) will be produced. This will result in early somatic ring loss and, thus, in a phenotypically recognisable XO male. Consequently, the correlation between repair ability and ring loss frequencies is a negative one. More efficient repair leads to a higher frequency of altered rings, whereas defective repair ability may ultimately result in less chromosome loss. A possible mechanism for repair of double-strand breaks is discussed by Szostak et al. (1983).

Ring-X males with doubly-marked Y chromosomes $\left(R(1) 2, y f / B^{S} Y y^{+}\right)$ were mated with females from each CT isofemale line, and normal male $\left(B^{S}\right)$ and ring loss male $\left(B^{+}\right)$progeny were scored to determine the effectiveness of maternal DNA repair in the CT lines. Between 75 and 100 matings were made for each line to obtain approximately 5000 scored progeny males. The intra-laboratory historical frequencies of spontaneous ring-X chromosome loss in crosses of $R(1) 2, y f / B^{s} Y y^{+}$males with $y^{2} w^{a}$ repair efficient females, and with females defective in excision repair $\left(y w^{a} s c m e i-9^{a}\right)$, 
postreplication repair ( $y$ pn mus (1)101 ${ }^{D 1}$; $c n b w$ ), or both excision and postreplication repair $\left(y w ; b w ;\right.$ st mus $(3) 302^{D 1}$ ) (Boyd and Setlow, 1976; Boyd et al., 1980; Boyd and Harris, 1981) were used as controls. Although we noted the major gynandromorphs that appeared in the progeny, our interest was in early ring loss and repair, and gynandromorph data will consequently not be reported here. In addition, the $F_{1}$ progeny of the ring-loss crosses were scored for spontaneous nondisjunction by $\mathrm{X}$-chromosome gain in the parental males and females.

Hybrid dysgenic mutator activity was quantified by measuring the rate of male recombination (Thompson and Woodruff, 1978). Male recombination is positively correlated with the rate of chromosome breakage and the induction of mutations attributable to movement of transposing genetic sequences (reviewed in Woodruff et al., 1983). CT line males were crossed with $d p b c n b w$ females (an $M$ laboratory line; see Bregliano and Kidwell, 1983 , for a description of the rules of hybrid dysgenesis), heterozygous $F_{1}$ males were test crossed to $d p b c n b w$ females, and $\mathrm{F}_{2}$ progeny were scored for recombination ( $d p=$ dumpy wings, $2 \mathrm{~L}-13.0 ; b=$ black body colour, $2 \mathrm{~L}-48 \cdot 5 ; c n=$ cinnabar eye colour, $2 \mathrm{R}-57 \cdot 5 ; b w=$ brown eye colour, $2 \mathrm{R}$ 104.5). See Lindsley and Grell (1968) for a description of mutants, balancer chromosomes and re-arrangements.

The data were analysed by the chi-square test or by the heterogeneity $G$ test (Sokal and Rohlf, 1981). A formula for the cumulative Poisson distribution (Owen, 1962) was used to compare the observed number of genetic changes per male with the expected value to identify clusters. Correlation co-efficients were determined by the Spearman rank correlation test, and regression analyses were carried out using the Statistical Package for the Social Sciences (SPSS).

\section{RESUlts}

The frequencies of spontaneous ring- $X$ chromosome loss in crosses with repair efficient and defective females are given in table 1 . Using genetically identical males, the crosses with repair defective females have a significantly lower frequency of ring loss (XO) male progeny than do crosses with the $y^{2} w^{a}$ repair efficient line. The largest reduction in ring loss is observed in

TABLE 1

Intra-laboratory historical frequencies of spontaneous ring-X chromosome loss in $R(1) 2$, $y f / B^{S} Y y^{+}$males mated with repair efficient and defective females

\begin{tabular}{|c|c|c|c|c|}
\hline Tested strain & Repair phenotype & $\begin{array}{l}\text { Males showing } \\
\text { ring loss }\end{array}$ & Total & $\%$ \\
\hline$y^{2} w^{a}$ & Repair efficient $\dagger$ & 625 & 25,451 & $2 \cdot 46$ \\
\hline$y w ; b w ; s t$ mus $(3) 302^{D I}$ & $\begin{array}{l}\text { Excision and postreplication } \\
\text { repair defective }\end{array}$ & 302 & 30,947 & $0.98^{*}$ \\
\hline$y w^{a}$ sc mei-9 $9^{a}$ & Excision repair defective & 403 & 20,056 & $2 \cdot 01^{*}$ \\
\hline ypn mus(1)101 ${ }^{D I} ; c n b w$ & Postreplication repair defective & 162 & 10,533 & $1 \cdot 54^{*}$ \\
\hline
\end{tabular}

${ }^{*} P<0.01$ in comparison with $y^{2} w^{a}$ frequency.

† Shown by resistance to methyl methanesulfonate killing (Brodberg and Woodruff, unpublished). 
crosses with postreplication repair defective females. Others have also observed alterations in the frequency of ring chromosome loss in the presence of repair defective mutations (Würgler and Graf, 1982; Zimmering, 1981). In addition, differential efficiency in the repair of spontaneous ring chromosome loss in laboratory lines has been reported by Würgler and Maier (1972), and a similar observation has been reported from studies of chemically-induced ring-X loss (Zimmering, 1981). Together, these results gave us confidence that it might be possible to measure genetic variation in repair ability found in strains isolated from natural populations.

The frequencies of spontaneous lethal mutations, ring loss, and male recombination in crosses with Chateau Tahbilk isofemale lines are shown in tables 2 and 3 . The lines have been divided into two sets, based upon population size at the time of collection.

TABLE 2

Frequencies of spontaneous lethal mutations, ring loss, and male recombination activity in 10 isofemale strains collected before population expansion at Chateau Tahbilk

\begin{tabular}{|c|c|c|c|c|c|c|c|c|c|}
\hline \multirow[b]{2}{*}{ Line } & \multicolumn{3}{|c|}{ Lethal Mutation } & \multicolumn{3}{|c|}{ Ring Loss } & \multicolumn{3}{|c|}{$\begin{array}{c}\text { Male } \\
\text { Recombination }\end{array}$} \\
\hline & lethals & total & $\%$ & loss & total & $\%$ & \# recomb. & $N$ & $\%$ \\
\hline CT-1 & 14 & 2295 & 0.61 & 104 & 7581 & $1 \cdot 37$ & 2 & 2905 & 0.07 \\
\hline CT-2 & 3 & 869 & 0.35 & 102 & 7731 & $1 \cdot 32$ & 0 & 3274 & 0.00 \\
\hline CT-3 & 1 & 1005 & $0 \cdot 10$ & 153 & 7335 & 2.09 & 1 & 1808 & 0.06 \\
\hline CT-4 & 13 & 2488 & 0.52 & 97 & 6900 & $1 \cdot 41$ & 5 & 2228 & 0.22 \\
\hline CT-5 & 4 & 1060 & 0.38 & 105 & 6391 & 1.64 & 3 & 2943 & $0 \cdot 10$ \\
\hline CT-6 & 6 & 2666 & 0.23 & 110 & 7424 & $1 \cdot 48$ & 41 & 2975 & $1 \cdot 38$ \\
\hline CT-7 & 7 & 1060 & 0.66 & 63 & 4384 & 1.44 & 4 & 3485 & 0.11 \\
\hline CT-8 & 4 & 1103 & 0.36 & 99 & 4732 & 2.09 & 3 & 2558 & 0.12 \\
\hline CT-9 & 2 & 1073 & $0 \cdot 19$ & 88 & 5763 & 1.53 & 0 & 2482 & 0.00 \\
\hline CT-10 & 4 & 1084 & 0.36 & 106 & 6241 & 1.70 & 0 & 2798 & 0.00 \\
\hline Total & 58 & 14,703 & 0.39 & 1027 & 64,482 & 1.59 & 59 & 27,456 & $0 \cdot 21$ \\
\hline
\end{tabular}

TABLE 3

Frequencies of spontaneous lethal mutations, ring loss, and male recombination activity in 10 isofemale strains collected after population expansion

\begin{tabular}{|c|c|c|c|c|c|c|c|c|c|}
\hline \multirow[b]{2}{*}{ Line } & \multicolumn{3}{|c|}{ Lethal Mutation } & \multicolumn{3}{|c|}{ Ring Loss } & \multicolumn{3}{|c|}{$\begin{array}{c}\text { Male } \\
\text { Recombination }\end{array}$} \\
\hline & lethals & total & $\%$ & loss & total & $\%$ & \# recomb. & $N$ & $\%$ \\
\hline CT-102 & 1 & 1131 & 0.09 & 57 & 6324 & 0.90 & 0 & 1873 & 0.00 \\
\hline CT-105 & 7 & 2327 & $0 \cdot 30$ & 88 & 6675 & $1 \cdot 32$ & 2 & 1934 & $0 \cdot 10$ \\
\hline CT-106 & 1 & 2370 & 0.04 & 117 & 6585 & $1 \cdot 78$ & 0 & 1601 & 0.00 \\
\hline CT-107 & 1 & 1163 & 0.09 & 70 & 5802 & $1 \cdot 21$ & 7 & 1490 & 0.47 \\
\hline CT-113 & 3 & 957 & 0.31 & 72 & 5659 & $1 \cdot 27$ & 4 & 1616 & 0.25 \\
\hline CT-114 & 0 & 1099 & 0.00 & 70 & 5473 & $1 \cdot 23$ & 0 & 1665 & 0.00 \\
\hline CT-118 & 5 & 1097 & 0.46 & 84 & 5852 & 1.44 & 1 & 1941 & 0.05 \\
\hline CT-119 & 1 & 2458 & 0.04 & 112 & 7243 & $1 \cdot 55$ & 4 & 1594 & $0 \cdot 25$ \\
\hline CT-122 & 2 & 1070 & 0.19 & 90 & 5753 & 1.56 & 1 & 999 & $0 \cdot 10$ \\
\hline CT-130 & 15 & 2453 & 0.61 & 90 & 6261 & 1.44 & 1 & 1286 & 0.08 \\
\hline Total & 36 & 16,125 & 0.22 & 850 & 61,627 & $1 \cdot 38$ & 20 & 15,999 & $0 \cdot 13$ \\
\hline
\end{tabular}


There were no significant correlations between lethal mutation and ring loss $(R=0.05, p=0.83)$, lethal mutation and male recombination $(R=0 \cdot 15$, $p=0.54)$ or ring loss and male recombination $(R=0.04, p=0.88)$. This can be illustrated further by comparing measurements in lines showing particularly high mutation or ring loss, such as CT-3 and CT-102. Both had the same level of lethal mutation, but CT-3 showed the highest frequency of ring loss and CT-102 showed the lowest of all lines.

The data in tables 2 and 3 include presumptive clusters, though removal of the rare clusters had no effect on the analysis. There were three clusters of lethals ( 5 lethals from a single male in CT-4, 4 lethals from a single male in CT-5, and 3 lethals from a single male in CT-6), and one large presumptive cluster of male recombinants $(36+++b w$ progeny in a single test of CT-6). Premeiotic ring loss is lethal in gonial cells, so clusters are not recovered.

There was a significant difference between overall lethal mutation frequencies in the small and the large population $\left(\chi^{2}=11 \cdot 1, p<0.01\right)$. Indeed, as measured by a step-wise multiple regression, approximately 21 per cent of the total variance in lethal frequencies is explained by the difference between sets. There was also a significant difference between ring loss in the two sets of lines $\left(\chi^{2}=9.64, p<0.01\right)$, with approximately 19 per cent of the variance in repair abilities being due to difference between sets. Even with the presumptive cluster of male recombinants in CT-6 included, there was no significant difference in the level of male recombination in the two sets $\left(\chi^{2}=2 \cdot 38\right)$. When all 20 lines are compared by the heterogeneity $G$ test, we find that all of those that have significantly lower frequencies of lethal mutations originated from the high density population (CT-106, CT-114 and CT-119), whereas three of the four lines with significantly higher frequencies of mutation were from the low-density population (CT-1, CT-4, CT-7 and CT-130). A similar analysis of ring-loss showed that three of four lines from the low-density population had significantly higher ring-loss frequencies (CT-3, CT-8, CT-10 and CT-106), whereas seven of ten lines with significantly lower frequencies were from the high-density population (CT-102, CT-105, CT-107, CT-113, CT-114, CT-118, CT-130, CT-1, CT-4 and CT-7). In addition, the three lines with significantly lower frequencies of male recombination were from the low-density population (CT-2, CT-9 and CT-10), whereas three of four lines with high frequencies of male recombination were from the high-density strains (CT-107, CT-113, CT-119 and CT-4).

In an attempt to measure the amount of variability for genetic damage and repair within an isofemale line, the frequencies of lethal mutations and ring-X chromosome loss were measured in additional runs with five CT lines. A high mutation line (CT-1) and a low mutation line (CT-119) were tested three and four additional times, respectively, over a three-year period. The results of these crosses are shown in table 4 . The CT-119 data are homogeneous over the five runs, whereas the CT-1 data are heterogeneous. If the June 1982 data from the CT-1 runs is removed, however, the other five runs are homogeneous. These data show that the spontaneous mutation rates of some isofemale lines that are maintained in the laboratory are uniform over time. In addition, it should be noted that the overall spontaneous mutation rate of the CT-1 line is about fourteen-fold higher than that of the CT-119 line.

In relation to variation within lines for ring-X chromosome loss, three additional experiments were performed with three lines (CT-2, CT-8 and 
TABLE 4

Frequencies of spontaneous lethal mutations in repeat experiments with low (CT-119) and high (CT-1) mutation lines

\begin{tabular}{ccccll}
\hline Line & $\begin{array}{c}\text { Date of } \\
\text { experiment }\end{array}$ & Lethals & Total & $\%$ & Heterogeneity $G$ test \\
\hline CT-119 & October 1980 & 0 & 1093 & 0 & \\
& March 1981 & 1 & 1365 & 0.07 & \\
& June 1982 & 1 & 1219 & 0.08 & \\
& August 1982 & 0 & 1032 & 0 & \\
& August 1982 & $\underline{0}$ & $\underline{1071}$ & $\underline{0}$ & \\
& & 2 & 5781 & $0.03^{*}$ & $G_{H(4)}=3 \cdot 23, P>0.05$ \\
CT-1 & June 1980 & 8 & 1150 & 0.70 & \\
& January 1981 & 6 & 1145 & 0.52 & \\
& June 1982 & 0 & 1138 & 0 & \\
& August 1982 & 5 & 1101 & 0.45 & \\
& August 1982 & 5 & 1214 & 0.41 & \\
& July 1983 & $\underline{4}$ & $\underline{1086}$ & $\underline{0.37}$ & \\
& & 29 & 6834 & $0 \cdot 42^{*}$ & $G_{H}(5)=11 \cdot 68, P<0.05 \dagger$ \\
\hline
\end{tabular}

$* P<0.01$.

$\dagger$ Without the June 1982 data, $G_{H(4)}=1.46, P>0.05$.

CT-10) over a one-year period. The results of these crosses are shown in table 5. The CT-2 and CT-10 data are homogeneous over the four experiments, whereas the CT- 8 data is heterogeneous. These data, plus our observations on intra-laboratory historical controls for lethal mutations and ring-chromosome loss, indicate that although some lines show stable ring-

\section{TABLE 5}

Frequencies of spontaneous ring-X chromosome loss in repeat experiments with three natural population lines

\begin{tabular}{|c|c|c|c|c|c|}
\hline Line & $\begin{array}{c}\text { Date of } \\
\text { Experiment }\end{array}$ & Ring Loss & Total & $\%$ & Heterogeneity $G$ Test \\
\hline \multirow[t]{5}{*}{ CT-2 } & August 1982 & 102 & 7731 & $1 \cdot 32$ & \\
\hline & December 1982 & 83 & 5434 & 1.53 & \\
\hline & April 1983 & 15 & 1168 & $1 \cdot 28$ & \\
\hline & June 1983 & 28 & 2139 & $1 \cdot 31$ & \\
\hline & & 228 & 16,472 & $1 \cdot 38^{*}$ & $G_{H(3)}=1 \cdot 21, P>0.05$ \\
\hline \multirow[t]{5}{*}{ CT -8} & August 1982 & 99 & 4732 & $2 \cdot 09$ & \\
\hline & December 1982 & 61 & 4962 & $1 \cdot 23$ & \\
\hline & April 1983 & 36 & 1674 & $2 \cdot 15$ & \\
\hline & June 1983 & 23 & 1493 & $1 \cdot 54$ & \\
\hline & & 219 & 12,643 & $1 \cdot 73^{*}$ & $G_{H(3)}=13.44, P<0.01$ \\
\hline \multirow[t]{5}{*}{ CT-10 } & October 1982 & 106 & 6135 & $1 \cdot 73$ & \\
\hline & January 1983 & 58 & 4570 & $1 \cdot 27$ & \\
\hline & July 1983 & 28 & 1755 & $1 \cdot 60$ & \\
\hline & July 1983 & 37 & 1860 & 1.99 & \\
\hline & & 229 & 14,320 & $1 \cdot 60^{*}$ & $G_{H(3)}=5 \cdot 70, P>0.05$ \\
\hline
\end{tabular}

* CT -10 vs. CT-2 and CT- 10 vs. CT-8, $P>0.05 ;$ CT-8 vs. CT-2, $P<0.01$. 
loss frequencies with time, there is more variability in ring- $\mathrm{X}$ chromosome loss within a line than there is for lethal mutations.

None of the CT natural population lines showed a significant frequency of nondisjunction.

\section{Discussion}

The data from this study show that there is significant genetic variation for spontaneous rates of genetic change and for repair ability within a natural population of $D$. melanogaster. However, these data show no correlation between repair ability and rates of genetic damage. The Chateau Tahbilk lines were observed to vary by as much as ten-fold for lethal mutation frequencies and two-fold for repair of broken ring chromosomes, and the frequencies of male recombination varied from zero to almost 0.5 per cent. Variation in the rates of spontaneous mutation and male recombination have been reported for other natural population lines of Drosophila (Plough, 1941 ; Dobzhansky, 1951 ; Dubinin, 1964; Woodruff et al., 1983), but there are no reports of the level of repair ability in natural population lines.

There were no significant correlations among frequencies of lethal mutations, male recombination and ring-chromosome loss in the CT lines. For example, lines did not show correlated high rates of mutation and male recombination coupled with defective repair. There are several possible explanations for the observed absence of correlations. First, the repair of spontaneous chromosome breakage (associated with ring- $X$ loss and male recombination) may occur by a mechanism(s) different from that of the repair of spontaneous gene mutations. Evidence in support of this explanation comes from the observation that an FM6 balancer strain of $D$. melanogaster with reduced repair ability for spontaneous lethal mutations (Valencia, personal communication) has efficient repair ability for spontaneous ring-X chromosome loss (Woodruff, unpublished). Second, male recombination seems to be induced by the movement of transposable DNA elements under the conditions of hybrid dysgenesis (Rubin, 1983), while the lethal mutations recovered in this study were assayed in the absence of hybrid dysgenesis. Finally, there is conflicting evidence concerning the role of repair in hybrid dysgenic induced mutagenesis. Excision or postreplication repair defective mutations (or a combination of defects in both repair pathways) do not affect the rate of hybrid dysgenic induced sex-linked recessive lethal mutations and male recombination (Slatko et al., 1984). On the other hand, Eeken and Sobels (1981) observed a significant increase in hybrid dysgenic induced visible mutations. These forward mutational events and male recombination are caused by presumptive insertions of $P$ DNA elements. In addition, the frequency of reversion of hybrid dysgenic induced visible mutations, which are caused by presumed excision of $P$ elements, is reduced in the presence of defective DNA repair (Eeken and Sobels, 1983).

A comparison of the frequencies of genetic change and repair in the two population samples showed an interesting, and somewhat surprising, result. The frequencies of sex-linked lethal mutations and ring- $X$ chromosome losses were significantly higher in the strains collected from the small resident population before expansion during the grape harvest. The frequencies of male recombination, which is probably caused by the movement of $P$-elements present in the CT chromosomes, were not significantly different 
in the two population samples. Molecular analysis of the CT chromosomes for the presence of $P$ elements is currently in progress and will be reported elsewhere. It is not clear why a low-density population would have a higher frequency of spontaneous mutation than a high-density population, particularly a high-density population with immigrants. Ives (1950) has argued that selection against modifers of mutation rates (mutators) would be less in larger populations and, hence, mutation rates in large populations should be higher. Maynard Smith (1976) has also discussed the possible interaction between population size and mutation rate. Expanding populations with unlimited food and breeding resources might be less affected by a high mutation rate than would a small population with limited resources (Levins, 1967). As an example, selection may be relaxed for increased mutation rates under the population flush stage of a flush-crash-founder cycle (Carson, 1975). On the other hand, a higher rate of mutation in a low density population might be due to inbreeding, which would lead to an increase in the frequency of homozygosity for recessive mutator genes.

In addition, beginning with Sturtevant (1937) others have suggested that genes which increase mutation rates in natural populations of sexual organisms will be selected against and any interference with the operation of this selection will increase the mutation rate (see discussions of this topic in Dobzhansky, 1951; Dubinin, 1964; Williams, 1966; Kimura, 1967; Leigh, 1970, 1973; Karlin and McGregor, 1974; Thompson and Woodruff, 1978; Gillespie, 1981 a, 1981 b; Woodruff et al., 1983). For example, hybridisation among migrants in the large-density winery population might be expected to increase mutation rates by the documented intraspecific hybrid release of mutator activity (Thompson and Woodruff, 1980; Woodruff et al., 1980; Shaw et al., 1983). As an indication of the possible impact of hybrid release on the rate of genetic change in nature, Woodruff and Thompson (1982b, and in preparation) have observed that the progeny from 25 of 90 crosses between natural population lines of $D$. melanogaster have a significantly higher frequency of spontaneous lethal mutations than do the base populations, and similar values have been observed for spontaneous breakage in hybrid progeny. One consequence of the intraspecific release of mutator activity is that high levels of rare genetic variants observed in hybrid zones (Hunt and Selander, 1973; Avise and Smith, 1974; Kilpatrick and Zimmerman, 1976; Gould and Woodruff, 1978; Sage and Selander, 1979; Smith, 1979; Moran et al., 1980; Greenbaum, 1981; Hafner, 1982; Peters, 1982; Barton et al., 1983) may be due to increased rates of mutation (Woodruff et al., 1979; Thompson and Woodruff, 1980), although intragenic recombination could also explain these variants (Golding and Strobeck, 1983). Support for increased rates of mutation as the cause of the increased genetic variation in hybrid zones comes from the observation that high frequencies of novel chromosome re-arrangements are observed in hybrid zones of grasshoppers and the re-arrangements are derived only from hybrid parents (Shaw et al., 1983).

The data herein clearly show that rates of genetic damage vary among population lines. However, the rates within some lines are constant in successive tests over fairly long periods of time. For example, with the exception of one experiment, the high mutation line (CT-1) and the low mutation line (CT-119) had uniform frequencies of lethal mutations in up to six independent experiments over a three-year period. There is a report 
of two other natural population lines with spontaneous lethal mutation frequencies of 0.19 and 0.40 per cent, in which the mutation rates remained constant for several years (Toropanova, 1960, quoted in Dubinin, 1964). Yet, others have reported that lines with high mutation rates show a rate reduction over time in the laboratory (Muller, 1941). Unless the high mutation frequency of 0.42 per cent is an optimum rate for the CT-1 line, it would be predicted that selection would act to reduce this rate. It is of interest, therefore, that the frequencies of mutation in successive experiments with the CT-1 line have gradually decreased with time (see table 4). However, since the frequency of mutation in the June 1980 experiment (8/1150-0.70 per cent) is not significantly higher than that of the recent July 1983 experiment (4/1086-0.37 per cent), additional tests need to be performed in the future to determine if the CT-1 rate continues to decrease to some minimum value.

In an initial attempt to identify the genetic basis of differences in mutation rates between natural population lines, we have inbred the CT-1 and CT-119 lines by single-pair sib matings for sixteen generations. By this inbreeding procedure, genetic factors that affect mutation rates will be made homozygous and can be more easily located and characterised. Preliminary results from the measurement of spontaneous sex-linked recessive lethal mutations in these inbred lines show that homozygosis of presumed mutator factors in the CT-1 line has not been possible. Two separate inbred lines of the CT-1 base stock showed low mutation frequencies of 0.08 per cent $(1 / 1,314)$ and $0 \cdot 16$ per cent $(2 / 1,242)$. The CT- 119 line continued to show low mutation frequencies in two inbred lines $(0 / 1,594$ and $2 / 1,470-0 \cdot 14$ per cent). The combined frequency of the CT- 1 inbred lines $(3 / 2,556-0 \cdot 12$ per cent) is significantly lower than the overall rate of the CT- 1 base population (29/6, 834-0.42 per cent). The frequencies of the inbred CT-1 19 lines and the CT-119 base population were not significantly different.

The loss of the high mutation rate in the CT-1 inbred lines may be an indication that lines with very high rates of spontaneous genetic damage do not survive. There are reports in the literature of lines with frequencies as high as one to two per cent spontaneous lethal mutation (Woodruff et al., 1983). However, individuals with rates higher than this may produce dominant lethal mutations and chromosome breakage events too frequently for progeny survival. It has been observed that high rates of presumed spontaneous dominant lethals occur in crosses with repair-defective mutations of D. melanogaster (Cooper and Zimmering, 1981; Graf et al., 1982; Brodberg et al., 1983).

Natural selection of mutation rates can probably not reduce the frequency of mutation to zero (Williams, 1966). Natural populations have high enough mutation rates to produce the rare favourable mutations that evolution is ultimately dependent upon. Yet, in the short term, an excessive rate of genetic change or an inefficient system of repair can be genetically disastrous.

Acknowledgements. We are grateful to Dr C. G. Nicholas Mascie-Taylor for help with statistical analysis, and Jeffery Boyce, Lee Pedersen and Mark Wood for their expert technical assistance. This work was supported by NSF grant BSR-8300025 to J.N.T. and N.S.F. grant BSR-8117063 to R.C.W., who is the recipient of Research Career Development Award K04-ES-00087 from NIEHS. 


\section{REFERENCES}

AVISE, J. C. AND SMITH, M. H. 1974. Biochemical genetics of sunfish. I. Geographic variation and subspecific intergradation in the bluegill, Lepomis macrochirus. Evolution, 28, 42-56.

BARTON, N. H., HALLIDAY, R. B. AND HEWITT, G. M. 1983. Rare electrophoretic variants in a hybrid zone. Heredity, 50, 139-146.

BOYD, J. B. AND HARRIS, P. V. 1981. Mutants partially defective in excision repair at five autosomal loci in Drosophila melanogaster. Chromosoma, 82, 249-257.

BOYD, J. B., HARRIS, P. V., OSGOOD, C. J. AND SMITH, K. E. 1980. Biochemical characterization of repair-deficient mutants of Drosophila. In Generoso, W. M. Shelby, M. D. and de Serres, F. J. (eds.) DNA Repair and Mutagenesis in Eukaryotes, Plenum Press, New York, pp. 209-222.

BOYD, J. B. AND SETLOW, R. B. 1976. Characterization of post-replication repair in mutagensensitive strains of Drosophila melanogaster. Genetics, 84, 507-526,

BREgliano, J. AND KIDWELl, M. G. 1983. Hybrid dysgenesis determinants. In Shapiro, J. A. (ed.) Mobile Genetic Elements, Academic Press, New York, 363-410.

BRODBERG, R. K., LYMAN, R. F. AND WOODRUFF, R. C. 1983. The induction of chromosome aberrations by cis-platinum(II)diaminodichloride in Drosophila melanogaster. Environmental Mutagenesis, 5, 285-297.

CARSON, H. L. 1975. The genetics of speciation at the diploid level. Amer. Nat, 109, 83-92.

COOPER, S. F. AND ZIMMERING, S. 1981. Genetic study on the effects of the repair-deficient mutant females mei-9 $9^{a}$, mei-41 ${ }^{D S}$, mus $101^{D 1}$, mus $104^{D 1}$, and mus302 ${ }^{D 1}$ of Drosophila on spontaneous and X-ray-induced chromosome loss in the paternal genome. Mutation Res., $81,345-356$.

DOBZHANSKY, TH. 1951. Genetics and the Origin of Species. Columbia University Press, New York.

DUbININ, N. P. 1964. Problems of Radiation Genetics. Oliver and Boyd, London.

EEKEN, J. C. J. AND SOBELS, F. H. 1981. Modification of MR mutator activity in repair-deficient strains of Drosophila melanogaster. Mutation Res., 83, 191-200.

EEKEN, J. C. J. AND SOBELS, F. H. 1983. The influence of deficiencies in DNA-repair on MR-mediated reversion of an insertion-sequence mutation in Drosophila melanogaster. Mutation Res., 110, 287-295.

GENEROSO, W. M., CAIN, K. T., KRISHNA, M. AND HUFF, S. W. 1979. Genetic lesions induced by chemicals in spermatozoa and spermatids of mice are repaired in the egg. Proc. Natl. Acad. Sci. U.S.A., 76, 435-437.

GILLESPIE, J. H. 1981 a. Mutation modification in a random environment. Evolution, 35, 468-476.

GILLESPIE, J. H. 1981 b. Evolution of the mutation rate at a heterotic locus. Proc. natl. Acad. Sci. U.S.A., 78, 2452-2454.

GOLDING, G. B. AND STROBECK, C. 1983. Increased number of alleles found in hybrid populations due to intragenic recombination. Evolution, 37, 17-29.

GOULD, S. J. AND WOODRUFF, D. S. 1978. Natural history of Cerion VIII: Little Bahama Bank-A revision based on genetics, morphometrics and geographic distribution. Bull. Mus. Comp. Zool., 148, 371-415.

GRAF, U., KAGI, A. AND WÜRGLER, F. E. 1982. Mutagenesis in spermatozoa of Drosophila melanogaster by cross-linking agents depends on the $\mathrm{mus}(1) 101^{+}$gene product in the oocyte. Mutation Res., 95, 237-249.

GREEN, M. M. 1976. Mutable and mutator loci. In Ashburner, M. and Novitski, E. (eds) The Genetics and Biology of Drosophila Vol. 1b, Academic Press, London, pp. 929946.

GREENBAUM, I. F. 1981. Genetic interactions between hybridizing cytotypes of the tent-making bat (Uroderma bilobatum). Evolution, 35, 306-321.

HAFNER, J. C. 1982. Genetic interactions at a contact zone of Uroderma bilobatum (Chiroptera: Phyllostomidae). Evolution, 36, 852-862.

HUNT, W. G. AND SELANDER, R. K. 1973. Biochemical genetics of hybridization in European house mice. Heredity, 31, 11-33.

IVES, P. T. 1950. The importance of mutation rate genes in evolution. Evolution, 4, 236-252.

KARLIN, S. AND McGREGOR, J. 1974. Towards a theory of the evolution of modifier genes. Theor. Pop. Biol. 5, 59-103.

KILPATRICK, C. W. AND ZIMMERMAN, E. G. 1976. Biochemical variation and systematics of Peromyscus pectoralis. J. Mamm., 57, 506-522.

KIMURA, M. 1967. On the evolutionary adjustment of spontaneous mutation rates. Genet. Res., Camb. 9, 23-34. 
LEIGH, B. 1976. Ring chromosomes and radiation induced chromosome loss. In Ashburner, M. and Novitski, E. (eds.) The Genetics and Biology of Drosophila, Vol. 1b, Academic Press, London, pp. 505-528.

LEIGH, E. G., JR. 1970. Natural selection and mutability. Amer. Nat., 104, 301-305.

LEIGH, E. G., JR. 1973. The evolution of mutation rates. Genetics, 73, 1-18.

LEVINS, R. 1967. Theory of fitness in a heterogeneous environment. VI. The adaptive significance of mutation. Genetics, 56, 163-178.

LINDSLEY, D. L. AND GRELL, E. H. 1968. Genetic Variations of Drosophila melanogaster. Carnegie Institution of Washington, publ. 627.

MASON, J. M. 1980. Spontaneous mutation frequencies in mutagen-sensitive mutants of Drosophila melanogaster. Mutation Res., 72, 323-326.

MAYNARD SMITH, J. 1976. What determines the rate of evolution? Amer. Nat., 110, 331-338.

MORAN, C., WILKINSON, P. AND SHAW, D. D. 1980 . Allozyme variation across a narrow hybrid zone in the grasshopper, Caledia captiva. Heredity, 44, 69-81.

MULLER, H. J. 1941. Induced mutations in Drosophila. Cold Spring Harbor Symp. Quant. Biol., 9, 290-308.

NEEL, J. v. 1983. Frequency of spontaneous and induced "point" mutations in higher eukaryotes. The Journal of Heredity, 74, 2-15.

OWEN, D. B. 1962. Handbook of Statistical Tables. Addison-Wesley Publ. Co., Inc., London.

PETERS, G. B. 1982. The recurrence of chromosome fusion in inter-population hybrids of the grasshopper Astractomorphia similis. Chromosoma, 85, 323-347.

Plough, H. H. 1941. Spontaneous mutability in Drosophila. Cold Spring Harbor Symp. Quant. Biol., 9, 127-137.

QUAH, S., VON BORSTEL, R. C. AND HASTINGS, P. J. 1980. The origin of spontaneous mutation in Saccharomyces cerevisiae. Genetics, 96, 819-839.

RACINE, R., BECK, A. AND WÜRGLER, F. E. 1979. The genetic control of maternal effects on mutations recovered from X-rayed mature Drosophila sperm. Mutation Res., 63, 87-100.

RubIN, G. M. 1983. Dispersed repetitive DNAs in Drosophila. In Shapiro, J. A. (ed.) Mobile Genetic Elements, Academic Press, New York, pp. 329-361.

SAGE, R. D. AND SELANDER, R. K. 1979. Hybridization between species of the Rana pipiens complex in central Texas. Evolution, 33, 1069-1088.

SHAW, D. D., WILKINSON, P. AND COATES, D. J. 1983. Increased chromosomal mutation rate after hybridization between two subspecies of grasshopper. Science, 220, 1165-1167.

SLATKO, B. E., MASON, J. M. AND wOODRUFF, R. C. 1984. The DNA transposition system of hybrid dysgenesis in Drosophila melanogaster can function despite defects in host DNA repair. Genet. Res., Camb.: in press.

SMITH, M. F. 1979. Geographic variation in genic and morphological characters in Peromyscuscalifornicus. J. Mamm., 60, 705-722.

SMITH, P. D., SNYDER, R. D. AND DUSENBERY, R. L. 1980. Isolation and characterization of repair-deficient mutants of Drosophila melanogaster. In Generoso, W. M. Shelby, M. D. and de Serres, F. J. (eds.) DNA Repair and Mutagenesis in Eukaryotes, Plenum Press, New York, pp. 175-188.

SOKAL, R. R. AND ROHLF, F. J. 1981. Biometry. W. H. Freeman and Co., San Francisco.

STURTEVANT, A. H. 1937. Essays on evolution I. On the effects of selection on mutation rate. Quart. Rev. Biol., 12, 464-467.

SZOSTAK, J. W., ORR-WEAVER, T. L., ROTHSTEIN, R. J. AND STAHL, F. W. 1983. The doublestrand-break repair model for recombination. Cell, 33, 25-35.

THOMPSON, J. N., JR. AND WOODRUFF, R. C. 1978. Mutator genes: Pacemakers of evolution. Nature, 274, 317-321.

THOMPSON, J. N., JR. AND WOODRUFF, R. C. 1980. Increased mutation in crosses between geographically separated strains of Drosophila melanogaster. Proc. Natl. Acad. Sci. U.S.A., $77,1059-1062$.

Willi AMS, G. C. 1966. Adaptation and Natural Selection. Princeton University Press. Princeton, N.J.

WOODRUFF, R. C. SLATKO, B. E. AND THOMPSON, J. N., JR. 1983. Factors affecting mutation rates in natural populations. In Ashburner, M. Carson, H. L. and Thompson, J. N., Jr. (eds.) The Genetics of Biology of Drosophila, Vol. 3c, Academic Press, London, pp. 37-124.

WOODRUFF, R. C. AND THOMPSON, J. N., JR. 1982a. Genetic factors that affect rates of spontaneous mutation and chromosome aberrations in Drosophila melanogaster, Cytogenetics and Cell Genetics, 33, 152-159.

WOODRUFF, R. C. AND THOMPSON, J. N., JR. 1982b. Hybrid release of mutator activity in crosses between natural population lines of Drosophila melanogaster. Genetics, 100, s75. 
WOODRUFF, R. C., THOMPSON, J. N., JR AND LYMAN, R. F. 1979. Intraspecific hybridization and the release of mutator activity. Nature, 278, 277-279.

WÜRGLER, F. E. AND GRAF, U. 1980. Mutation induction in repair-deficient strains of Drosophila. In Generoso, W. M. Shelby, M. D. and de Serres, F. J. (eds.) DNA Repair and Mutagenesis in Eukaryotes, Plenum Press, New York, pp. 223-240.

WÜRGLER, F. E. AND GRAF, U. 1982. Stability of Drosophila melanogaster chromosomes replicating for the first time in a repair-deficient cell. Mutation Res., 92, 99-106.

WÜRGLER, F. E. AND MAIER, P. 1972. Genetic control of mutation induction in Drosophila melanogaster. I. Sex-chromosome loss in X-rayed mature sperm. Mutation Res., $15,41-53$.

VIJAYALAXMI, EVANS, H. J. RAY, J. H. AND GERMAN, J. 1983. Bloom's syndrome: Evidence for an increased mutation frequency in vivo. Science, 221, 851-853.

ZIMMERING, S. 1981. Review of the current status of the mei-9 test for chromosome loss in Drosophila melanogaster: An assay with radically improved detection capacity for chromosome lesions induced by methyl methanesulfonate (MMS), dimethylnitrosamine (DMN), and especially diethylnitrosamine (DEN) and procarbazine. Mutation Res., 83, 69-80. 